\title{
A mathematical framework for dissecting normative foundations of
} objective-driven conservation decisions

Guillaume Latombe ${ }^{1,2^{*}}$, Bernd Lenzner ${ }^{1}$, Anna Schertler ${ }^{1}$, Stefan Dullinger ${ }^{3}$, Michael Glaser ${ }^{1}$, Ivan Jarić4,5, Aníbal Pauchard ${ }^{6,7}$, John R. U. Wilson ${ }^{8,9}$, Franz Essl ${ }^{1,9}$

${ }^{1}$ BioInvasions, Global Change, Macroecology - Group, Department of Botany and Biodiversity

10 Research, University Vienna, Rennweg 14, 1030 Vienna, Austria

$11{ }^{2}$ Institute of Evolutionary Biology, The University of Edinburgh, King's Buildings, Edinburgh

12 EH9 3FL, United Kingdom

13 Division of Conservation Biology, Vegetation and Landscape Ecology, Department of Botany

14 and Biodiversity Research, University of Vienna, Rennweg 14, 1030 Vienna, Austria

$15{ }^{4}$ Biology Centre of the Czech Academy of Sciences, Institute of Hydrobiology, Na Sádkách

16 702/7, 37005 České Budějovice, Czech Republic

17 University of South Bohemia, Faculty of Science, Department of Ecosystem Biology,

18 Branišovska 1645/31a, 37005 České Budějovice, Czech Republic

$19{ }^{6}$ Laboratorio de Invasiones Biológicas (LIB), Facultad de Ciencias Forestales, University of

20 Concepcion Victoria 631, Concepción, Chile

$21{ }^{7}$ Institute of Ecology and Biodiversity (IEB), Santiago, Chile

$22{ }^{8}$ South African National Biodiversity Institute, Kirstenbosch Research Centre, Claremont 7735,

23 South Africa

$24{ }^{9}$ Centre for Invasion Biology, Department of Botany and Zoology, Stellenbosch University,

25 Private Bag X1, Matieland 7602, South Africa

28 *Corresponding author: latombe.guillaume@gmail.com 


\section{$30 \quad$ Abstract}

Perspectives in conservation are based on a variety of value systems and normative postulates.

33 Such differences in how people value nature and its components lead to different evaluations of the morality of conservation goals and approaches, and often underlie disagreements in the formulation and implementation of environmental management policies. Specifically, whether a specific conservation decision (e.g. killing feral cats to save birds threatened with extinction) is viewed as appropriate or not can vary among people with different value systems. Here, we present a conceptual, mathematical framework that is intended to serve as a heuristic tool to clarify normative postulates in conservation approaches based on the expected consequences of management. Although it is not intended to replace more complex philosophical discursive approaches and moral reasoning, its purpose is to highlight how fundamental differences between value systems can lead to different prioritizations of available management options and offer a common ground for discussion. We compare how management decisions would likely be viewed under three different idealised value systems (ecocentric conservation, new conservation, and sentientist conservation). We illustrate the utility of the framework by applying it to case studies involving invasive alien species, rewilding, and trophy hunting. By making value systems and their consequences in practice explicit, the framework facilitates debates on contested conservation issues. Finally, we believe dissecting the normative postulates on which conservation decisions are based will facilitate understanding and addressing conservation conflicts.

Keywords: environmental management; impact; invasive alien species; moral values; rewilding; speciesism; trophy hunting 


\section{INTRODUCTION}

The consideration of the moral relationship between humans and nature and the consequent ethical obligations for conservation is relatively recent in Western culture. Environmental ethics only emerged as an academic discipline in the 1970s (Brennan and Lo, 2016) and the concepts of values, duty, and animal welfare, are now increasingly appreciated in applied ecology and conservation (e.g. Díaz et al., 2018; Dubois et al., 2017). These concepts are complex and the formulation and implementation of environmental management policies is often associated with conflicts between different groups of stakeholders and between people with different values and interests, for example for the management of charismatic alien species (Crowley et al., 2017; Jarić et al., 2020; Redpath et al., 2013). An examination of how value systems could be explicitly accounted for in decision making could offer opportunities for better identifying conflicts, potentially helping to resolve them, and overall improve environmental management.

Value systems consider more or less inclusive communities of moral patients (the elements with intrinsic or inherent value towards which humans, considered here as the community of moral agents, are considered to have obligations; in the following, we refer to the community of moral patients as the moral community, for simplification; Table 1), ranging from humans (anthropocentrism), to further incorporate sentient beings (sentientism), living beings (biocentrism), and collectives (such as species and ecosystems; ecocentrism) (Table 1, Figure 1). The definition of moral communities can also be influenced by additional elements (such as spatial elements in the case of nativism), and, at the assessor level, by personal experience. These value systems underlie different sets of explicit or implicit normative postulates that define different conservation approaches (e.g. Soulé, 1985). If the normative postulates of different value systems differ (and excluding considerations that moral reasoning, experience, etc., may change one's value system), conflicts can arise between different groups of stakeholders whose members share common moral values (e.g. Crowley et al., 2017). In particular, conservationists who value biodiversity per se [as defined initially by Soulé (1985), called hereafter 'traditional conservation' (Table 1)] can be at odds with those who value biodiversity based on human welfare and economic aspects [including 'new conservation' (Kareiva and Marvier, 2012)], leading to heated debates in the literature (Doak et al., 2015; Kareiva, 2014; Soulé, 2014), or 
with those based on animal welfare ['conservation welfare' (Beausoleil et al., 2018), or, to a certain extent, 'compassionate conservation' (Driscoll and Watson, 2019; Hayward et al., 2019; Wallach et al., 2018)].

In the following, our aim is to conceptualize and decompose value systems in an explicit and potentially quantifiable fashion using a common mathematical framework, and to explore their repercussions for the perception of conservation management actions by stakeholders with different value systems. We argue that doing so allows for explicit comparison between these perceptions to identify sources of potential conflicts. First, we recapitulate four archetypal value systems in environmental affairs and relate them to different conservation philosophies. Since identifying commonalities in the perspectives of different parties is key in conflict management (Redpath et al., 2013), we then introduce a formal framework to conceptualise these value systems, and examine how it can be applied to clarify different perspectives. Finally, we discuss opportunities for identifying commonalities between different value systems that may enable identifying widely acceptable solutions to otherwise polarising issues.

Here, we will focus on a Western perspective of value systems that have been internationally considered for environmental policies and the management of nature (e.g. Mace, 2014). The archetypes of value systems and of conservation approaches were chosen for their importance in the past and present literature and their clear differences, to illustrate our framework. We acknowledge this is a small part of the global diversity of value systems. It would be interesting to see if our framework could be applied to other contexts, to identify its limitations.

\section{ENVIRONMENTAL ETHICS AND CONSERVATION}

\section{From the valuation of humans to that of ecosystems: a complex spectrum of} perspectives.

The Western perspective of moral valuation encompasses a diverse set of value systems with respect to the components of nature that form the community of moral patients. Traditionally, 
one can distinguish at least four archetypal value systems: anthropocentrism, sentientism, biocentrism, and ecocentrism (Palmer et al., 2014; Rolston III, 2003) (Table 1; Figure 1).

Anthropocentrism values nature by the benefits it brings to people through ecosystem services, which encompasses economic, biological, and cultural benefits humans can derive from nature (Díaz et al., 2018). One justification for anthropocentrism is that humans are (arguably) the only self-reflective moral beings, and people are therefore both the subject and object of ethics (Rolston III, 2003), therefore constituting the moral community (Table 1). In an anthropocentric system, individuals from non-human species only have value based on their benefits or disservices for humans (instrumental or non-instrumental).

Sentientism considers that humans and all sentient animals value their life, and experience pleasure, pain, and suffering. All sentient individuals should therefore also be part of the moral community (i.e. have an intrinsic value). In this view, it is the sentience (e.g. measured through cognitive ability, Singer, 2009), rather than species themselves, that has intrinsic value.

Biocentrism considers that life has intrinsic value. Although different perspectives on why life has value exist (see e.g. Taylor, 2011), all living organisms are valued equally for being alive, and not differently based on any other trait.

Some ecocentric, or holistic, value systems consider that ecological collectives, such as species or ecosystems, have intrinsic value, independently from the individuals that comprise them. Species can have different values, i.e. speciesism (Table 1), and these values can be influenced by a multitude of factors, discussed in more details below.

In practice, the separation between these different archetypes is blurry, and values given to different species may vary under the same general approach. For example, biocentrism can range from complete egalitarianism between organisms, i.e. universalism (Table 1), to a gradual valuation resembling sentientism. These four value systems can also interact with other systems that use other criteria than the intrinsic characteristics of individuals to define the moral community. For example, nativism is a system that values organisms indigenous to a spatial 
location or an ecosystem over those that have been anthropogenically introduced. Nativism can therefore interact with any of the four systems presented above to alter the value attributed to a species in a given context. Finally, the attribution of values to individuals from different species can be deeply embedded in the individual psychologies of the assessor (Palmer et al., 2014; Waytz et al., 2019). Values and personal interests interact in making and expressing moral judgements (Essl et al., 2017). Thus, the archetypes of value systems presented above are rarely expressed in a clear and obvious fashion.

To account for the different elements that can be combined to create the concept of value, in the following, we distinguish between 'intrinsic', 'inherent', and 'utilitarian', value (our definitions; Table 1). Intrinsic value is the value possessed by an individual or collective as defined by one of the systems above, and is therefore independent of context. Intrinsic value is based on objective criteria (i.e. independent of the assessor), such as cognitive ability (but the choice of these criteria is subjective). This has been termed "objective intrinsic value" by others (Sandler, 2012). Inherent value is the value of an individual, species or ecosystem that results from the combination of its intrinsic value (which can be considered to be null or non-existent) and context-specific and subjective factors (note that other scholars have used 'inherent' differently, e.g. Regan, 2004; Taylor, 1987; here it corresponds to what has also been termed "subjective intrinsic value"; Sandler, 2012). These factors include charisma (Courchamp et al., 2018; Jarić et al., 2020), anthropomorphism (Tam et al., 2013), organismic complexity (Proença et al., 2008), neoteny (Stokes, 2007), cultural importance (Garibaldi and Turner, 2004), religion (Bhagwat et al., 2011), or parochialism (Waytz et al., 2019), or more generally the relationship between humans and elements of nature (Chan et al., 2016) (Table 1). For example, some alien species that did not have any inherent value prior to their introduction have been incorporated in local cultures, therefore providing them a novel and higher inherent value such as horses being linked to a strong local cultural identity in some parts of the USA (Rikoon, 2006). Inherent value can often be considered to be fixed at the time scale of a management action, but can nonetheless vary over short time scales in some situations (see the example of the Oostvaardersplassen nature reserve below). Utilitarian value is determined only from an anthropocentric perspective. It is context-dependent and can change rapidly, for example in the case of commercial exploitation. 
Conservation practices can historically be divided into three main categories, closely related to specific systems of moral valuation (Mace, 2014). At one extreme, a 'nature for itself' (Table 1) view mostly excludes humans from the assessment of the efficacy of conservation management actions. This ecocentric perspective is the foundation of traditional conservation as defined by Soulé (1985), and relies on the four following normative postulates: "diversity of organisms is good," "ecological complexity is good," "evolution is good," and "biotic diversity has intrinsic value" (Soulé, 1985). It historically underlies widely-used conservation tools, like the IUCN Red List of Threatened Species (IUCN, 2019), in which threat categories are defined in terms of probability of extinction (Mace and Lande, 1991) (i.e. a species-level criterion aimed at preserving biodiversity). Ecocentrism is often not limited to the valuation of species, but can encompass wider collectives, i.e. assemblages of species and functions, or ecosystems. This other perspective is captured, for example, by the IUCN Red List of Ecosystems (IUCN-CEM, 2016), and it is strongly reflected in international conservation-legislation such as the Convention on Biological Diversity (UNEP CBD, 2010). In the following we refer to traditional conservation as an ecocentric value system where species are intrinsically valuable (nature for itself; Figure 1) and humans are mostly excluded from management. We acknowledge that this is an archetypal view of traditional conservation, and is used here simply for illustrative purposes.

By contrast the anthropocentric 'nature for people' perspective (Mace, 2014) values species and ecosystems only to the extent that they contribute to the wellbeing of humans. These values encompass ecosystem services that help sustain human life (Bolund and Hunhammar, 1999) or economic assets (Fisher et al., 2008), and can rely on the assessment of species and ecosystem services in terms of their economic value (Costanza et al., 1997), which can be considered as the most general form of utilitarian value, and has also been termed economism (Norton, 2000). The 'nature for people' perspective can nonetheless incorporate additional measures linked to human wellbeing, such as poverty alleviation or political participation. This more holistic measure of impacts on humans is exemplified by 'new conservation', also termed 'social conservation' (Doak et al., 2015; Kareiva, 2014; Miller et al., 2011) (Table 1). It has been argued that such an anthropocentric perspective will, by extension, help and even be necessary to maximize the 
conservation of nature (Kareiva and Marvier, 2012). This view was first laid out as the convergence hypothesis (Norton, 1986). It is nonetheless important to note that the exact set of normative postulates proposed by the proponents of new conservation is not clearly defined (Miller et al., 2011), leading to differences of interpretation and heated debates in recent years (Doak et al., 2015; Kareiva, 2014; Kareiva and Marvier, 2012; Soulé, 2014).

Environmental pragmatism (Katz and Light, 2013; Norton, 1984), proposed the notion of weak anthropocentrism, in which the value of elements of the environment is not only utilitarian, but defined by the relationship between humans and nature (Chan et al., 2016), and therefore is influenced by context and people's experience (see also the notion of inherent value described above). More recently, the necessity to account for the interdependence between the health of nature and human wellbeing (i.e. 'people and nature' Mace, 2014) has been advocated in the United Nations Sustainable Development Goals (Weitz et al., 2018). Similarly, "nature-based solutions" is an approach endorsed by the IUCN, which aims at protecting, sustainably managing, and restoring, natural or modified ecosystems, to simultaneously provide human wellbeing and biodiversity benefits (Cohen-Shacham et al., 2016). The 'One Health' approach, endorsed by the Food and Agriculture Organization, the World Health Organization, and the World Organisation for Animal Health also acknowledges the interdependence between the state of ecosystems and human health and zoonoses (Gibbs, 2014). The difference between people and nature and new conservation approaches therefore lies in the fact that it merges anthropocentric and ecocentric systems, rather than considering that the latter will be addressed by focusing on the former (see Section "Nature despite/for/and people" below for details).

Finally, although the animal right movement, based on sentientism, originated in the $19^{\text {th }}$ century (Salt, 1894), it has not, to our knowledge, been formally considered in conservation approaches until recently. Two main approaches can be found in the literature. Conservation welfare (Beausoleil et al., 2018) is a consequentialist perspective that considers conservation under the prism of animal welfare maximisation. Compassionate conservation (Ramp and Bekoff, 2015; Wallach et al., 2018), also incorporates animal sentience, but from a virtue ethics perspective. Although conservation welfare aims at aligning with more traditional conservation approaches presented above (Beausoleil et al., 2018), compassionate conservation appears to be set on 
different values and proposes, for example, to incorporate emotion to provide insight in conservation (Batavia et al., 2021).

\section{FRAMING MORAL VALUES FOR OBJECTIVE-DRIVEN CONSERVATION}

\section{Formulation of a mathematical framework.}

Many of the conflicts in conservation are grounded in the failure to identify and formalize differences in world views, which contain elements of the four archetypes presented above, influenced by cultural norms, economic incentives etc. (Essl et al., 2017). Here, we propose a mathematical formulation as a method to clarify moral discourses in conservation, based on a consequentialist perspective. We therefore consider an objective-driven type of conservation. Our purpose is not to argue about the relevance of consequentialism vs. deontology, or on the place of virtue ethics in conservation. Rather, we consider that, from a management perspective, conservation necessarily includes objective-driven considerations. A better understanding of how and why objectives can differ between stakeholders is therefore useful to anticipate and manage potential conflicts. In particular, we argue that defining concepts as mathematical terms can make differences in value systems and their normative postulates more transparent to all participants of the discourse. Doing so can help to identify and facilitate the discussion of shared values and incompatibilities between different environmental policies and management options (Miller et al., 2011), and contribute to manage conflicts (Redpath et al., 2013). In a similar vein, Parker et al. (1999) proposed a mathematical framework for assessing the environmental impacts of alien species. This work was highly influential in the conceptualisation of biological invasions (being cited over 2,000 times until April 2021 according to Google Scholar), rather than by its direct quantitative application. We also acknowledge that this approach has specific limitations, which are discussed below.

Our mathematical formalisation conceptualises the consequences of environmental management actions. We argue that it can account for different value systems, including the anthropocentric, sentientist, biocentric and species-based ecocentric systems (see Appendix S1 for an extension to 
ecocentrism beyond species and considering wider collectives, i.e. ecosystems), while also accounting for cultural and personal contexts. These consequences $C$ can be conceptualised as a combination of the impact of an action on the different species or individuals involved and the value given to said species and individuals under different value systems as follows:

$$
C=\sum_{\text {species } s} \bar{I}_{S} \times V_{s} \times N_{S}^{a}
$$

where $\bar{I}_{S}$ is a function (e.g. mean, maximum, etc.) of the impact (direct and indirect) resulting from the management action on all individuals of species $s, V_{s}$ is the inherent value attributed to an individual of species $s$ (as described above), $N_{s}$ is the abundance of species $s$, and $a$ determines the importance given to a species based on its abundance or rarity (and enables to account for the importance of a species rather than an individual, see below). The unit of $C$ depends on how other parameters are defined, which themselves depend on the value system considered. In summary, the higher the impact on species with high values, the higher the consequences.

Inherent value $V_{s}$ can have a monetary unit, or be unit-less, for example, depending on how it is defined. Our definition of inherent value here is extremely broad, as the purpose of this work is not to define what such value should be. Rather, it is flexible to encompass multiple perspectives and the subjectivity of the assessor, and can be based on intrinsic, utilitarian or relational values (Chan et al., 2016).

\section{The parameter $a$ can take both positive and negative values. A value of 1 means that} consequences are computed over individuals. If all values $V_{s}$ were the same, $a=1 \mathrm{implies}$ that all individuals in the moral community (Table 1) weigh the same when computing $\mathrm{C}$, irrespective of the species they belong to. This is typical of individual-centred value systems, i.e. sentientism, and biocentrism, whose characteristics (sentience and life) are defined at the individual level (note that since anthropocentrism only includes individuals from one species as moral patients, the term $\mathrm{N}_{\mathrm{s}}{ }^{\mathrm{a}}$ is irrelevant in this case). As a result, impacts on larger populations would weigh more on the consequences. As $a$ decreases towards 0 , the correlation between the value of a species and its abundance decreases. For $a=0$, the consequence of a management action 
becomes abundance-independent. For $a<0$, rare species would be valued higher than common species (or the same impact would be considered to be higher for rare species), for example due to the higher risk of extinction. $a>1$ would give a disproportionate weight to abundant species, which are often important for providing ecosystem services (Gaston, 2010).

The impact $I_{s}$ is computed at the individual level. It can be limited to the probability of death of individuals or changes in per capita recruitment rate, thus allowing to compute a proxy for extinction risk if $a \leq 0$, but can also include animal welfare, biophysical states, etc. Different measures of impact can be considered under a same system of value, in which case Eq.1 should be applied to each one separately (see section "Application of the mathematical framework" below for details). $I_{S}$ can only encompass the direct impact of a management action (in a narrow view that only the direct impact of humans, i.e. the moral agents, should be considered, and that the direct impacts from non-moral agents should not be considered), but also its indirect impact resulting from biotic interactions (considering that, in the context of management and therefore human actions, these indirect impacts are ultimately the result of the actions of the moral agents). One would therefore need to define a baseline corresponding to either i) the lowest possible measurable level of impact (e.g. being alive if death is the only measure of impact, or no sign of disease and starvation for biophysical states; this would obviously be more complicated for welfare), so that $I$ would only be positive; ii) the current state of the system, in which case impacts could be positive or negative for different species; or iii) the past state of a system, for example prior to the introduction of alien species (see Rohwer and Marris, 2021 for a discussion on the notion of ecosystem integrity). The duration over which to measure such impact should also be determined. The exact quantification of impact will be influenced by different value systems and personal subjectivity. Some impacts may be considered incommensurable (Essl et al., 2017), therefore falling out of the scope of the framework. The average impact $\bar{I}_{S}$ over all considered individuals from a species could be used as a measure at the species-level, as different individuals may experience different impacts, if the management action targets only part of a given population. Using the average impact is not without shortcomings though, since it does not account for potential discrepancies in impacts suffered by different individuals in a population. In other words, to which point do "the needs of the many outweigh the needs of the few" (Littmann, 2016)? Other measures such as the maximum impact experienced by 
individuals, or more complex functions accounting for the variability of impacts and values across individuals of a same species may also be used, to account for potential disproportionate impacts on a subset of the considered individuals. Under anthropocentric perspectives, impacts are influenced by the utilitarian values of species.

\section{Application of the mathematical framework.}

For each measure of impact and each system of values, Equation 1 produces relative rather than absolute values. The values of consequences $C$ of a management action under different value systems and measure of impact cannot be directly compared with each other, because the unit and range of values of $C$ can vary between value systems. Instead, Equation 1 can be used to rank a set of management actions for each value system or measure of impact based on their assessed consequences, to identify management actions representing consensus, compromises or conflicts amongst value systems.

If different types of impacts are considered simultaneously under a value system, Equation 1 might rank management actions differently for these different impacts under the same system of moral values, potentially leading to moral dilemmas. Similarly, some actions might not follow moral norms compared to others despite having more desirable consequences. For example, killing individuals may be considered less moral, but more efficient to preserve biodiversity or ecosystem services than using landscape management. Solving these moral dilemmas is complex, and beyond the scope of this publication, but approaches such as multi-criteria decision analyses (MCDA, Huang et al., 2011) may offer avenue to do so (Goetghebeur and Wagner, 2017). Similarly, environmental conflicts will likely emerge when comparing the rankings generated by Equation 1 under different value systems considering different distributions of values, and different measures of impact. MCDA (Wittmer et al., 2006) and operational research (Kunsch et al., 2009), have also been proposed to resolve such conflicts. We nonetheless argue that, regardless of the capacity to resolve environmental conflicts (or moral dilemmas), being able to understand where these conflicts emerge from in Equation 1 can only be beneficial for decision making. 
In the following, we show how, despite the difficulty to quantify the variables described above, understand conservation disputes.

\section{NATURE DESPITE/FOR/AND PEOPLE}

Over the past decade there has been some debate between proponents of traditional conservation, and those of new conservation (Table 1), as each group assumes different relationships between nature and people. Here, we show how the formal conceptualisation of Equation 1 could help clarifying the position of the new conservation approach in response to its criticisms (Kareiva, 2014).

\section{Nature despite people and traditional conservation}

Traditional conservation is based on an ecocentric value system and seeks to maximize diversity of organisms, ecological complexity, and to enable evolution (Soulé, 1985). For simplification, we will consider an extreme perspective of traditional conservation, championed by 'fortress conservation' (Büscher, 2016; Siurua, 2006), i.e. excluding humans from the moral community. To capture these aspects, consequences $C$ in Equation 1 can be more specifically expressed as follows:

$$
C=\sum_{\text {species s (excluding humans) }} \bar{I}_{s} \times V_{s} \times N_{S}{ }^{\mathrm{a}<0}
$$




\section{Nature for people and new conservation}

New conservation considers that many stakeholders ("resource users", Kareiva, 2014) tend to have an anthropocentric value system, and that conservation approaches that do not incorporate such a perspective will likely not succeed at maximizing diversity of organisms (Kareiva, 2014; Kareiva and Marvier, 2012). Under anthropocentrism, species are only conserved due to their utilitarian value, i.e. their effect on $I$ for humans, rather than based on an inherent value $V$. Different groups of stakeholders are likely to be impacted differently (e.g. different monetary

$$
C=\sum_{\text {stakeholders } t} \bar{I}_{t} \times V_{t} \times N_{t}
$$

where $\bar{I}_{t}$ is the average impact of management on the group of stakeholders $t$, including indirect impacts through the effect of management of non-human species, $V_{t}$ is the value of the group of stakeholders $t$, and $N_{t}$ is its abundance. Note that including inherent values $V_{t}$ in Equation 3 does not imply that we consider that different humans should be valued differently, but that is a view that some people have, and this needs to appear here to capture the full spectrum of perceived consequences of a management action.

New conservation holds an ambiguous perspective, stating that it should make "sure people benefit from conservation", while at the same time does not "want to replace biological-diversity based conservation with a humanitarian movement" (Kareiva, 2014). Using our framework, we interpret this as considering that one can design management actions that minimize consequences $C$ under both Equations 2 and 3 (i.e. a mathematical expression of the convergence hypothesis; Norton, 1986). The link between biodiversity and ecosystem services is strongly supported, even if many unknowns remain (Cardinale et al., 2012; Chivian and Bernstein, 2008), implying that high biodiversity can indeed support the provision of ecosystem services to humans. Such an approach will necessarily distinguish between "useful" species and others, and impacts will be perceived differently by different groups of stakeholders. Considering multiple types of impacts (economic benefits/losses, access to nature, health, etc.) while accounting for cultural 
differences, would increase the pool of useful species (comparing the resulting equation outputs using, for example, MCDA). The outcome of the two approaches would then potentially be more aligned with each other. This broad utilitarian perspective is captured in the most recent developments of new conservation approaches, which consider a wide range of nature contributions to people, rather than just ecosystem services (Díaz et al., 2018).

\section{People and nature}

People and nature views seek to simultaneously benefit human wellbeing and biodiversity. Under this perspective, Equations 2 and 3 should therefore be combined in a single approach, for example using MCDA (Huang et al., 2011), to capture a more diverse set of value systems than Equations 2 and 3 alone, even if the two approaches generate divergent results.

We expressed traditional and new conservation with Equations 2 and 3, which correspond to extreme interpretations of these two approaches (excluding humans or considering specific utilities of species). Doing so illustrates how our mathematical framework can capture in an explicit fashion the pitfalls of failing to explicitly define normative postulates for conservation approaches. As a result, Equations 2 and 3 will likely generate conflicting results in the ranking of different management actions, especially if few types of impacts are considered. The debates over new conservation have taken place in a discursive fashion, which has not provided a clear answer to the values defended by this approach (Doak et al., 2015; Kareiva, 2014; Soulé, 2014). It has therefore been argued that the normative postulates of new conservation need to be more explicitly defined (Miller et al., 2011). Our framework could help doing so, by being more explicit about how new conservation would be defined relative to the traditional conservation and the people and nature perspective through the addition of specific terms to Equation 3 and a thorough comparison of the resulting equations. In particular, it would be interesting to explore, if inherent values are attributed to different species under a new conservation approach, how these values are determined compared to a traditional conservation approach (e.g. relational vs. intrinsic value; Chan et al., 2016) and how their distributions differ.

\section{THE CASE OF ANIMAL WELFARE}


The question of if and how animal welfare should be integrated into conservation practice is conscious and sentient animals" (Wallach et al., 2018). It opposes the killing of sentient invasive alien species; the killing of sentient native predators threatening endangered species; or the killing of sentient individuals from a given population to fund broader conservation goals.

Despite the near-universal support of conservation practitioners and scientists for compassion towards wildlife and ensuring animal welfare (e.g. Hayward et al., 2019; Oommen et al., 2019; Russell et al., 2016), compassionate conservation has sparked vigorous responses (Driscoll and Watson, 2019; Griffin et al., 2020; Hampton et al., 2018; Hayward et al., 2019; Oommen et al., 2019). Amongst the main criticisms of compassionate conservation is that the absence of action can result in unintended detrimental effects and increased suffering for individuals of other or the same species (including humans), as a result of altered biotic interactions across multiple trophic levels, i.e. "not doing anything" is an active choice that has consequences (Table 2). However, since compassionate conservation is not based on consequentialism, it uses different criteria to assess the appropriateness of conservations actions (but see Wallach et al., 2020 for responses to some criticisms). Our purpose here is not to discuss the relevance or irrelevance of virtue ethics for conservation (see Griffin et al., 2020 for such criticism). Instead, we propose discussing animal welfare from the perspective of consequentialism (Hampton et al., 2018), i.e. more aligned with the approach of conservation welfare (Beausoleil et al., 2018), and to show how it may be aligned with or oppose the traditional and new conservation approaches.

\section{A mathematical conceptualisation of animal welfare}

A consequentialist, sentientist perspective aims at maximizing happiness, or conversely minimising suffering, for all sentient beings, an approach also termed 'utilitarianism' (Singer, 
1980; Varner, 2008). Suffering is therefore considered as a measure of impact (or, in mathematical terms, impact is a function of suffering, which can be expressed as $I\left(S_{s}\right)$ in Equation 1).

It has become widely accepted that animals experience emotions (de Waal, 2011). Emotions have been shown to be linked to cognitive processes (Boissy and Lee, 2014), which differ greatly among species (MacLean et al., 2012), and behavioural approaches have been used to evaluate and grade emotional responses (e.g. Désiré et al., 2002; but see Shriver, 2006 and Bermond et al., 2008 for different conclusions about the capacity of animals to experience suffering). We therefore postulate that the quantification of suffering is conceptually feasible in the context of the heuristic tool presented here. In a utilitarian approach, the inherent value of a species would therefore be a function of its capacity to experience emotions and suffering $E_{s}$, which can be expressed as $V\left(E_{s}\right)$ instead of $V_{s}$ in Equation 1.

Under these considerations for defining impact and value of species, the consequences of a conservation action can be computed as:

$$
C=\sum_{\text {species s }} \overline{I\left(S_{S}\right)} \times V\left(E_{S}\right) \times N_{S}^{a=1}
$$

\begin{abstract}
Although $V\left(E_{S}\right)$ should be measured in an objective fashion, many factors may influence the
\end{abstract} relationship between the inherent value and the emotional capacity of a species. For example, high empathy (Table 1) from the observer will tend to make the distribution uniform, whereas anthropomorphism and parochialism (Table 1) may lead to higher rating of the emotional capacities of species phylogenetically close to humans or with which humans are more often in contact, such as pets. Finally, we assumed that $a=1$, to give equal importance to any individual regardless of the abundance of its species, as suffering and wellbeing are usually considered at the individual level (Beausoleil et al., 2018).

\title{
Assessing suffering in the presence and absence of conservation management actions
}


The short-term suffering resulting from pain and directly caused by lethal management actions, such as the use of poison to control invasive alien species (Twigg and Parker, 2010) or the use of firearms and traps to cull native species threatening other native species (e.g. Proulx et al., 2016) or humans (e.g. Gibbs and Warren, 2015), is the most straightforward type of suffering that can be assessed, and is usually sought to be minimised in all conservation approaches. Suffering can have many other causes, and suffering of an individual may be assessed through a wide variety of proxies, including access to food and water, death, number of dead kin for social animals, physiological measurements of stress hormones, etc. Suffering can take various forms, and commensurability can be an issue (Table 2), making the distinction between the morality of lethal actions and non-lethal suffering complex. Non-lethal suffering can result from unfavourable environmental conditions (e.g. leading to food deprivation) and occur over long periods, while lethal actions could be carried out in a quick, non-painful fashion (e.g. Shao et al., 2018), and even lead to improved animal welfare (Wilson and Edwards, 2019), but may be deemed immoral.

The concept of animal welfare and how to measure it is extremely complex (Beausoleil et al., 2018), and defining it precisely is beyond the scope of this study. We nonetheless advocate a conceptual approach that takes into account indirect consequences of management actions within a certain timeframe and consider uncertainty (Table 2). Direct and indirect biotic interactions may be explicitly modelled to quantify the impact on animals and their suffering. Simulation models can also make projections on how populations may change in time, accounting for future suffering.

\section{Are traditional conservation and animal welfare compatible?}

It has been argued that sentientism and ecocentrism are not fully incompatible (Varner, 2011). The relationship between biodiversity and animal suffering can be formalised more clearly using the traditional conservation and the sentientist Equations 2 and 4, to explore if the same management action can minimize the consequences evaluated using the two equations (see also Appendix S2 for the application of the framework to theoretical cases). The main difference with the traditional vs new conservation debate here is that Equations 2 and 4 share a number of 
species, whereas the new conservation Equation 3 only contains humans, which are excluded from Equation 2. Even though the variables of Equation 4 differ from those of Equation 2 ( $V$ and $I$ are computed differently, and the value of $a$ is different), it is possible that these equations will vary in similar way for different management actions due to their similar structure, although this would depend on the variety of impacts on humans that are considered in Equation 3. Finally, as for the people and nature approach, the consequences of sentientist and ecocentric approaches can be evaluated in combination, as suggested by conservation welfare (Beausoleil et al., 2018), using tools such as MCDA (Huang et al., 2011; Wittmer et al., 2006).

One issue that may be irreconcilable between ecocentric approaches such as traditional conservation and approaches based on sentientism is the fate of rare and endangered species with limited or no sentience. Under utilitarian sentientism, the conservation of non-sentient species ranks lower than the conservation of sentient species, and consequently they are not included in Equation 4. For example, endangered plant species that are not a resource for the maintenance of sentient populations would receive no attention, as there would be few arguments for their conservation. Traditional conservation would focus on their conservation, as they would have a disproportionate impact in Equation 2, due to low abundance leading to a high value for $N^{a<0}$.

Finally, it is important to note that the current body of knowledge shows that the link between biodiversity and animal welfare mentioned above especially applies to the increase of native biodiversity. Local increase of biodiversity due to the introduction of alien species may only be temporary due to extinction debt (Kuussaari et al., 2009) and often results in a reduction of ecosystem functioning (Cardinale et al., 2012). Therefore, it is important to distinguish between nativism (Table 1) and the detrimental effects of invasive alien species on biodiversity and ecosystem functioning and services (Bellard et al., 2016). Nativism would result in increasing the inherent value $V_{s}$ of native species (Figure 1), whereas in the second case, insights from science on the impact of invasive alien species would modify the distribution $I(S)$ rather than the distribution $V_{s}$. This can also apply to native species whose impacts on other species, such as predation, are increased through environmental changes (Carey et al., 2012).

\section{UNRESOLVED QUESTIONS AND LIMITATIONS}


This framework shares similarities with mathematical approaches used in conservation triage (Bottrill et al., 2008), but has two crucial differences. First, conservation triage is an ecocentric perspective with variables that are comparatively easy to quantify. Bottrill et al. (2008) provided an example using phylogenetic diversity as a measure of value $V$, and a binomial value $b$ to quantify biodiversity benefit that can be interpreted as the presence or absence of a species (i.e. $I$ $=1 / \mathrm{b}$ ). Because it is ecocentric, local species abundance is not considered, which corresponds to setting $a=0$. In this example, consequences $(C)$ in the general Equation 1 are therefore defined simply by $V / b$.

In contrast, our framework allows much more flexibility to encompass a range of value systems, as shown above. Given that the data needed for quantifying parameters of Equations 1 to 4 related to value, impact, emotional capacity and suffering are scarce and often very difficult to measure, this framework in its current form would nonetheless be difficult to use as a quantitative decision tool to evaluate alternative management actions, contrary to triage equations. Rather, our equations decompose the question underlying many controversies around management decisions in conservation: what or who is valued, how, and by how much?

There are nonetheless a number of approaches that may be used to develop quantification schemes for the different parameters of the framework. Grading systems may be developed to assess impact and suffering based on various indicators, including appearance, physiology, and behaviour (Beausoleil et al., 2018; Broom, 1988). For assessing the value of different species, questionnaires may be used to assess how different species are valued by people, and influenced by their social and cultural background, similar to what has been done to assess species charisma (e.g. Albert et al., 2018; Colléony et al., 2017). It will nonetheless be important to acknowledge the corresponding uncertainties in the assessment of impact and value, differences in perception among societal groups for different taxa and potential shifts in perception over time (Table 2).

The second difference from conservation triage is that the latter considers additional criteria that were not addressed here, including feasibility, cost, and efficiency (including related uncertainties). The combination of these different perspectives calls for appropriate methods to 
include them all in decision making, which can be done using MCDA (Huang et al., 2011). Here, good communication and transparency of the decision process is key to achieve the highest possible acceptance across stakeholders, and to avoid biases in public perception (see case studies below for examples).

The issue of spatial and temporal scale also warrants consideration (Table 2). In the case of a species that may be detrimental to others in a given location but in decline globally, the spatial scale and the population considered for evaluating the terms of Equations 1 to 4 is crucial to determine appropriate management actions. Similarly, management actions may also result in a temporary decrease in welfare conditions for animals, which may increase later on (Ohl and Van der Staay, 2012), or the impacts may be manifested with a temporal lag. In that case, determining the appropriate time period over which to evaluate the terms of Equations 1 to 4 will not be straightforward. Impacts will be of different importance depending on whether they occur in the short- or long-term, especially since long-term impacts are harder to predict and involve higher uncertainty. Discount rates (Table 2) may therefore be applied, in a similar way they are applied to the future effects of climate change and carbon emissions (Essl et al., 2018), or to assess the impact of alien species (Essl et al., 2017).

Equations 1 to 4 assume that all individuals from a given species have the same value or emotional capacities (or use the average of the value across individuals). However, intraspecific differences in value may be important for conservation. For example, reproductively active individuals contributing to population growth/recovery may be given a higher value in an ecocentric perspective. Trophy hunters might prefer to hunt adult male deer with large antlers. Intraspecific value may also vary spatially, for example between individuals in nature reserves or in highly disturbed ecosystems. Equation 1 may therefore theoretically be adapted to use custom groups of individuals with specific values within species, similar to Equation 3.

Finally, it is crucial to account for biotic interactions in our framework to comprehensively assess the indirect impacts of management actions on different species (Table 2). Some species with low values $V_{s}$ in a certain value system may be crucial for assessing the impact $I_{S}$ on other species. These biotic interactions will therefore determine the time frame over which the 
framework should be applied, as impacts on one species at a given time may have important repercussions in the future. These biotic interactions can be complex, and several tools, such as simulation models and ecological network analyses can be used to address them. Concepts such as keystone species (Mills et al., 1993) can also offer a convenient way to overcome such complexity by modifying $V_{s}$ rather than $\bar{I}_{S}$. Let us assume that a management action will have a direct impact on a keystone species, which will result in indirect impacts on multiple other species with inherent values. Increasing the value of the keystone species can result in the same assessment of $C$ as to explicitly model the biotic interactions and compute the resulting indirect impacts $\bar{I}_{S}$.

\section{CASE STUDIES ILLUSTRATING ETHICAL CONFLICTS IN CONSERVATION DECISIONS}

In the following, we present three case studies where conservation actions have either failed, had adverse effects, or were controversial, and we explore how our framework can help to identify normative postulates underlying these situations. Although these case studies have been discussed at length in the articles and reports we cite, we argue that our framework helps capturing the different components of the surrounding controversies in a more straightforward and objective fashion than using a discursive and sometimes emotionally loaded language.

\section{Invasive alien species management: the case of the alien grey squirrel in Italy}

The grey squirrel (Sciurus carolinensis) is native to North America and was introduced in various locations in Europe during the late nineteenth and the twentieth century (Bertolino, 2008). It threatens native European red squirrel (Sciurus vulgaris) populations through competitive exclusion, and is also a vector of transmission of squirrel poxvirus in Great Britain (Schuchert et al., 2014). Furthermore, it has wider impacts on woodlands and plantations, reducing value of tree crops, and potentially affects bird populations through nest predation (Bertolino, 2008). 
Based on the impacts of the grey squirrel, an eradication campaign was implemented in 1997 in Italy, with encouraging preliminary results (Genovesi and Bertolino, 2001). However, this eradication campaign was halted by public pressure from animal rights movements. The strategy of the animal rights activists consisted in (i) humanising the grey squirrel and using emotive messages (referring to grey squirrels as "Cip and Ciop", the Italian names of the Walt Disney "Chip and Dale" characters) and (ii) minimising or denying the effect of grey squirrel on native taxa, especially the red squirrel (Genovesi and Bertolino, 2001). In addition, the activists did not mention (iii) the difference in abundance between a small founding population of grey squirrels that could be eradicated by managers, and a large population of native red squirrels that would be extirpated or severely impacted by grey squirrels if control was not implemented.

Genovesi \& Bertolino (2001) explain that the main reason for the failure of the species management is a different perspective on primary values: the eradication approach was underlain by species valuation, following traditional conservation, whereas the animal right activists and the public were more sensitive to animal welfare. However, the application of our framework reveals some inconsistencies in the animal right activists' arguments that could have been used to advocate for the eradication approach. Translating this situation in our framework indicates that (i) the humanisation of the grey squirrel consists of increasing the perception of its emotional capacity $E_{g s}>E_{r s}$ (and therefore $V\left(E_{g s}\right)>V\left(E_{r s}\right)$ ), (ii) minimising the impact of the grey squirrel is equal to restricting the time scale to a short one and to likely minimising the amount of suffering $S$ caused by grey squirrels on other species, i.e. $S_{g s}=S_{r s}$ (and therefore $\left.I\left(S_{g s}\right)=I\left(S_{r s}\right)\right)$ without management and $S_{g s}>S_{r s}$ (and therefore $\left.I\left(S_{g s}\right)>I\left(S_{r s}\right)\right)$ under management, and (iii) not mentioning differences in species abundance corresponds to setting $a=0$. Following these three points, the consequences under management $C_{m}=I\left(S_{g s}\right) \times V\left(E_{g s}\right)+I\left(S_{r s}\right) \times V\left(E_{r s}\right)$ are higher than without management, due to the increase in $V\left(E_{g s}\right)$ and $I\left(S_{g s}\right)$. The application of our framework therefore allows to clarify a discourse whose perception could otherwise be altered because of techniques such as appeal to emotion.

The framework can thus be used to provide recommendations for what the advocates for the eradication campaign would have needed to have done: i) increase the value $E_{r s}$ of red squirrels in a similar way as what was done for grey squirrels, so that their relative values compared to 
grey squirrels would remain the same as before the communication campaign by the animal right activists; ii) better explain the differences in animal suffering caused by the long-term presence of the grey squirrel compared to the short-term, carefully designed euthanasia protocol, which would avoid a subjective perception of the distribution of $S$; and iii) highlight the differences in the number of individuals affected. The consequences would then be computed as $C=V\left(E_{g s}\right) \times$ $I\left(S_{g s}\right) \times N_{g s}+V\left(E_{r s}\right) \times I\left(S_{r s}\right) \times N_{r s}$. In that case, assuming for simplification the same suffering through euthanasia for grey squirrels as red squirrels suffer from the grey squirrels, and the same value to individuals of each species (i.e. avoiding nativism), the mere differences $N_{r s}>$ $N_{g s}$ in abundance would lead to a higher value of $C$ without management. This would further increase by extending the impacts of grey squirrels to other species, as mentioned above.

A more fundamental issue, however, is that in some value systems it would not be acceptable to actively kill individuals, even if that meant letting grey squirrels eliminate red squirrels over long periods of time (e.g. Wallach et al., 2018). The reluctance to support indirectly positive conservation programs is a common issue (Courchamp et al., 2017). Whether an acceptable threshold on consequences over which killing individuals could be determined through discussion would depend, in part, on the willingness of the affected parties to compromise.

\section{De-domestication: the case of Oostvaardersplassen nature reserve}

De-domestication, the intentional reintroduction of domesticated species to the wild is a recent practice in conservation that raises new ethical questions related to the unique status of these species (Gamborg et al., 2010). Oostvaardersplassen is a Dutch nature reserve where two domesticated species of large herbivores (Heck cattle, Bos primigenius, and konik horses, Equus ferus caballus) have been 'rewilded' in addition to the reintroduction of the red deer (Cervus elaphus) to act as landscape engineers by grazing (ICMO2, 2010). The populations increased rapidly, as natural predators are missing and population regulation was not conducted, as a result of a 'non-intervention-strategy'. The project was widely criticized when a considerable number of individuals died from starvation during a harsh winter, resulting in the introduction of population reduction by culling weak animals in order to prevent starvation (other approaches, 
such as the reintroduction of large predators were discarded due to lack of experience and too many uncertainties in efficiency, ICMO2, 2010).

From a traditional conservation perspective, disregarding animal welfare and focusing on species diversity and ecological restoration, the project was a success. The introduction of the three herbivore species led to sustainable populations (despite high winter mortality events), and ensured stability of bird populations without the need for further interventions (ICMO2, 2010), i.e. the conditions of many species were improved (the impact was lowered), leading to lower consequences $C$ overall (Equation 2). However, the welfare of individuals from the three charismatic large herbivorous species became a point of conflict. Interestingly, it appears that the conflict was driven by a shift in attitude, from considering the herbivore species as a natural way to manage the grasslands to being part of the ecosystem changed the value $V_{s}$, or by the importance given to their emotional capacity $E_{s}$ (Ohl and Van der Staay, 2012), therefore leading to increasing the consequences $C=V\left(E_{S}\right) \times I\left(S_{S}\right) \times N_{S}{ }^{1}$ under sentientism, with $S_{s}$ and $N_{s}$ constant. Temporal changes in the distributions of the $V$ and $E$ variables should therefore be taken into account when implementing conservation management actions, and even monitored through time in a way similar to adaptive management approaches. Another possible explanation for this shift in attitude is that the notion of responsibility (Table 2) affected the moral aspect of culling that should then be considered in parallel to its consequences. If culling animals can be considered acceptable in some cases, it may not be the case if these individuals were purposefully introduced.

As a result, the reserve management has examined a number of sustainable measures to improve the welfare of individuals from the three species (therefore decreasing $S_{S}$ to compensate the increase in $V_{s}$ ). Among those were recommendations to increase access to natural shelter in neighbouring areas of woodland or forestry, to create shelter ridges to increase survival in winter as an ethical and sustainable solution, and to use early culling to regulate populations and avoid suffering from starvation in winter (ICMO2, 2010). This example shows how a combination of two complementary management actions (the rewilding of the OVP and the provision of shelter) led to minimised consequences under both the traditional conservation and the sentientist 
Equations 2 and 4, whereas only rewilding would increase consequences under Equation 4. Culling may still face opposition based on moral arguments though.

\section{Trophy hunting}

Trophy hunting, the use of charismatic species for hunting activities, has been argued to be good for conservation when revenues are reinvested properly into nature protection and redistributed across local communities, but faces criticisms for moral reasons (Di Minin et al., 2016; Lindsey et al., 2007a). The action of killing some individuals to save others might be incompatible with a deontological perspective, but, assuming a consequentialist perspective, the framework can be applied to formalise the assessment of different management options (we are not considering canned hunting here, the practice of farming animals for the specific purpose of being hunted).

In traditional conservation, trophy hunting is desirable if it directly contributes to the maintenance of species diversity. The potential of trophy hunting to contribute to the maintenance of biodiversity is via creating economic revenues, i.e. an anthropocentric perspective, and it therefore falls under the umbrella of new conservation. In theory, trophy hunting should lead to lower consequences than doing nothing for both the traditional and new conservation (Equations 2 and 3), and therefore for the 'people and nature' approach, as they are in this case not independent from each other (Lindsey et al., 2007b). Many social and biological factors currently affect the efficacy of trophy hunting as a conservation tool. Corruption and privatisation of the benefits have sometimes prevented the revenues to be reinvested into conservation, but also to be redistributed across local communities, whereas doing so has been shown to increase their participation in conservation actions with proven benefits for local biodiversity (Di Minin et al., 2016). In other words, a decrease in the anthropocentric Equation 2 leads to a decrease in the ecocentric Equation 3. In addition, trophy hunting can lead to unexpected evolutionary consequences (Coltman et al., 2003), overharvesting of young males (Lindsey et al., 2007a), and disproportionate pressure on threatened species (Palazy et al., 2013, 2012, 2011) and therefore to population declines and potential detrimental effects on biodiversity. Despite these issues, it has been argued that banning trophy hunting may create replacement activities that would be more detrimental to biodiversity (Di Minin et al., 2016). 
From an animal welfare perspective, trophy hunting appears to be in direct contradiction with a decrease in animal suffering, and has been criticised by proponents of compassionate conservation (Wallach et al., 2018). However, as for the culling of invasive alien species, we suspect the story is more complex. First, there may be direct benefits for animal welfare, if money from trophy hunting is reinvested in protection measures against poaching (which is likely more detrimental to the hunted individuals). Second, to our knowledge, only few studies have compared the welfare of individual animals to quantify the elements of the sentientist Equation 4 (for example assessed through access to resources) in areas where trophy hunting is practiced and where it is not. Given the links between biodiversity and animal welfare described above, it seems plausible that good practice in trophy hunting may benefit the welfare of individuals from other and from the same species.

\section{CONCLUSIONS}

823 identify hidden commonalities between seemingly antagonistic stances. We hope that this 824 framework can foster debates on contested conservation issues, and will ultimately contribute to 825 a broader appreciation of different viewpoints. In an increasingly complex world shaped by 826 human activities, this is becoming ever more important. 
bioRxiv preprint doi: https://doi.org/10.1101/2020.09.04 282947; this version posted April 14, 2021. The copyright holder for this preprint

(which was not certified by peer review) is the author/funder, who has granted bioRxiv a license to display the preprint in perpetuity. It is made available under aCC-BY 4.0 International license.

$829 \quad$ Acknowledgements

831 We thank Franck Courchamp, Vincent Devictor, Jordan Hampton, Jonathan Jeschke, and Thomas

832 Potthast for extremely useful comments on this manuscript. GL, BL, AS, FE, and SD were

833 supported by the Austrian Science Foundation FWF (BiodivERsA-Belmont Forum Project 'Alien

834 Scenarios', grant no. I 4011-B32; grant no. I3757-B29). AP was funded by Conicyt PIA CCTE

835 AFB170008. IJ acknowledges support by the J. E. Purkyně Fellowship of the Czech Academy of

836 Sciences. JRUW thanks the South African Department of Forestry, Fisheries, and the

837 Environment (DFFtE) for funding noting that this publication does not necessarily represent the

838 views or opinions of DFFtE or its employees. 


\section{REFERENCES}

Albert, C., Luque, G.M., Courchamp, F., 2018. The twenty most charismatic species. PLoS One 13, e0199149. https://doi.org/10.1371/journal.pone.0199149

Alexander, L., Moore, M., 2016. Deontological Ethics. Stanford Encycl. Philos.

Allen, C., Trestman, M., 2017. Animal Consciousness. Stanford Encycl. Philos.

Batavia, C., Nelson, M.P., Bruskotter, J.T., Jones, M.S., Yanco, E., Ramp, D., Bekoff, M., Wallach, A.D., 2021. Emotion as a source of moral understanding in conservation. Conserv. Biol. n/a. https://doi.org/https://doi.org/10.1111/cobi.13689

Beausoleil, N.J., Mellor, D.J., Baker, L., Baker, S.E., Bellio, M., Clarke, A.S., Dale, A., Garlick, S., Jones, B., Harvey, A., 2018. "Feelings and Fitness" not "Feelings or Fitness" - the raison d'être of conservation welfare, which aligns conservation and animal welfare objectives. Front. Vet. Sci. 5, 296.

Bellard, C., Cassey, P., Blackburn, T.M., 2016. Alien species as a driver of recent extinctions. Biol. Lett. 12, 20150623. https://doi.org/10.1098/rsbl.2015.0623

Bermond, B., Armstrong, S.J., Botzler, R.G., 2008. A neuropsychological and evolutionary approach to animal consciousness and animal suffering. Anim. Ethics Read. 2, 99-112.

Bertolino, S., 2008. Introduction of the American grey squirrel (Sciurus carolinensis) in Europe: a case study in biological invasion. Curr. Sci. 95, 903-906.

Bhagwat, S.A., Dudley, N., Harrop, S.R., 2011. Religious following in biodiversity hotspots: challenges and opportunities for conservation and development. Conserv. Lett. 4, 234-240. https://doi.org/10.1111/j.1755-263X.2011.00169.x

Boissy, A., Lee, C., 2014. How assessing relationships between emotions and cognition can improve farm animal welfare. Rev. Sci. Tech. 33, 103-110.

Bolund, P., Hunhammar, S., 1999. Ecosystem services in urban areas. Ecol. Econ. 29, 293-301. https://doi.org/10.1016/S0921-8009(99)00013-0

Bottrill, M.C., Joseph, L.N., Carwardine, J., Bode, M., Cook, C., Game, E.T., Grantham, H., Kark, S., Linke, S., McDonald-Madden, E., 2008. Is conservation triage just smart decision making? Trends Ecol. Evol. 23, 649-654. https://doi.org/10.1016/j.tree.2008.07.007

Brennan, A., Lo, Y.-S., 2016. Environmental Ethics. Stanford Encycl. Philos.

Broom, D.M., 1988. The scientific assessment of animal welfare. Appl. Anim. Behav. Sci. 20, 519. https://doi.org/10.1016/0168-1591(88)90122-0

Büscher, B., 2016. Reassessing fortress conservation? New media and the politics of distinction in Kruger National Park. Ann. Am. Assoc. Geogr. 106, 114-129. https://doi.org/10.1080/00045608.2015.1095061

Cardinale, B.J., Duffy, J.E., Gonzalez, A., Hooper, D.U., Perrings, C., Venail, P., Narwani, A., Mace, G.M., Tilman, D., Wardle, D.A., Kinzig, A., Daily, G.C., Loreau, M., Grace, J.B., Larigauderie, A., Srivastava, D.S., Naeem, S., 2012. Biodiversity loss and its impact on humanity. Nature 486, 59. https://doi.org/10.1038/nature11148

Carey, M.P., Sanderson, B.L., Barnas, K.A., Olden, J.D., 2012. Native invaders-challenges for science, management, policy, and society. Front. Ecol. Environ. 10, 373-381. https://doi.org/10.1890/110060

Chan, K.M.A., Balvanera, P., Benessaiah, K., Chapman, M., Díaz, S., Gómez-Baggethun, E., Gould, R., Hannahs, N., Jax, K., Klain, S., Luck, G.W., Martín-López, B., Muraca, B., Norton, B., Ott, K., Pascual, U., Satterfield, T., Tadaki, M., Taggart, J., Turner, N., 2016. Opinion: Why protect nature? Rethinking values and the environment. Proc. Natl. Acad. Sci. 113, 1462 LP - 1465. https://doi.org/10.1073/pnas.1525002113 
Chivian, E., Bernstein, A., 2008. Sustaining life: how human health depends on biodiversity. Oxford University Press.

Cohen-Shacham, E., Walters, G., Janzen, C., Maginnis, S., 2016. Nature-based solutions to address global societal challenges. IUCN, Gland. Switz. 97.

Colléony, A., Clayton, S., Couvet, D., Saint Jalme, M., Prévot, A.-C., 2017. Human preferences for species conservation: Animal charisma trumps endangered status. Biol. Conserv. 206, 263-269. https://doi.org/10.1016/j.biocon.2016.11.035

Coltman, D.W., O’Donoghue, P., Jorgenson, J.T., Hogg, J.T., Strobeck, C., Festa-Bianchet, M., 2003. Undesirable evolutionary consequences of trophy hunting. Nature 426, 655. https://doi.org/10.1038/nature02177

Costanza, R., D’Arge, R., De Groot, R., Farber, S., Grasso, M., Hannon, B., Limburg, K., Naeem, S., O'neill, R. V, Paruelo, J., Raskin, R.G., Sutton, P., van den Belt, M., 1997. The value of the world's ecosystem services and natural capital. Nature 387, 253-260. https://doi.org/10.1016/S0921-8009(98)00020-2

Courchamp, F., Fournier, A., Bellard, C., Bertelsmeier, C., Bonnaud, E., Jeschke, J.M., Russell, J.C., 2017. Invasion biology: specific problems and possible solutions. Trends Ecol. Evol. 32, 13-22. https://doi.org/10.1016/j.tree.2016.11.001

Courchamp, F., Jaric, I., Albert, C., Meinard, Y., Ripple, W.J., Chapron, G., 2018. The paradoxical extinction of the most charismatic animals. PLoS Biol. 16, e2003997. https://doi.org/10.1371/journal.pbio.2003997

Crowley, S.L., Hinchliffe, S., McDonald, R.A., 2017. Conflict in invasive species management. Front. Ecol. Environ. 15, 133-141. https://doi.org/10.1002/fee.1471

Dawkins, M.S., 2008. The science of animal suffering. Ethology 114, 937-945.

de Waal, F.B.M., 2011. What is an animal emotion? Ann. N. Y. Acad. Sci. 1224, 191-206. https://doi.org/10.1111/j.1749-6632.2010.05912.x

Désiré, L., Boissy, A., Veissier, I., 2002. Emotions in farm animals:: a new approach to animal welfare in applied ethology. Behav. Processes 60, 165-180. https://doi.org/10.1016/S03766357(02)00081-5

Di Minin, E., Leader-Williams, N., Bradshaw, C.J.A., 2016. Banning trophy hunting will exacerbate biodiversity loss. Trends Ecol. Evol. 31, 99-102. https://doi.org/10.1016/j.tree.2015.12.006

Díaz, S., Pascual, U., Stenseke, M., Martín-López, B., Watson, R.T., Molnár, Z., Hill, R., Chan, K.M.A., Baste, I.A., Brauman, K.A., 2018. Assessing nature's contributions to people. Science (80-. ). 359, 270-272. https://doi.org/10.1126/science.aap8826

Doak, D.F., Bakker, V.J., Goldstein, B.E., Hale, B., 2015. What is the future of conservation?, in: Protecting the Wild. Springer, pp. 27-35. https://doi.org/10.5822/978-1-61091-551-9_4

Driscoll, D.A., Watson, M.J., 2019. Science denialism and compassionate conservation: response to Wallach et al. 2018. Conserv. Biol. 33, 777-780. https://doi.org/10.1111/cobi.13273

Dubois, S., Fenwick, N., Ryan, E.A., Baker, L., Baker, S.E., Beausoleil, N.J., Carter, S., Cartwright, B., Costa, F., Draper, C., 2017. International consensus principles for ethical wildlife control. Conserv. Biol. 31, 753-760. https://doi.org/10.1111/cobi.12896

Essl, F., Erb, K., Glatzel, S., Pauchard, A., 2018. Climate change, carbon market instruments, and biodiversity: focusing on synergies and avoiding pitfalls. Wiley Interdiscip. Rev. Clim. Chang. 9, e486. https://doi.org/10.1002/wcc.486

Essl, F., Hulme, P.E., Jeschke, J.M., Keller, R., Pyšek, P., Richardson, D.M., Saul, W.-C., Bacher, S., Dullinger, S., Estévez, R.A., Kueffer, C., Roy, H.E., Seebens, H., Rabitsch, W., 2017. 
Scientific and normative foundations for the valuation of alien-species impacts: thirteen core principles. Bioscience 67, 166-178. https://doi.org/10.1093/biosci/biw160

Farah, M.J., 2008. Neuroethics and the problem of other minds: Implications of neuroscience for the moral status of brain-damaged patients and nonhuman animals. Neuroethics 1, 9-18.

Fisher, B., Turner, K., Zylstra, M., Brouwer, R., De Groot, R., Farber, S., Ferraro, P., Green, R., Hadley, D., Harlow, J., 2008. Ecosystem services and economic theory: integration for policy-relevant research. Ecol. Appl. 18, 2050-2067. https://doi.org/10.1890/07-1537.1

Gamborg, C., Gremmen, B., Christiansen, S.B., Sandoe, P., 2010. De-domestication: ethics at the intersection of landscape restoration and animal welfare. Environ. Values 19, 57-78.

Garibaldi, A., Turner, N., 2004. Cultural keystone species: implications for ecological conservation and restoration. Ecol. Soc. 9.

Gaston, K.J., 2010. Valuing common species. Science (80-. ). 327, 154-155. https://doi.org/10.1126/science.1182818

Genovesi, P., Bertolino, S., 2001. Human dimension aspects in invasive alien species issues: the case of the failure of the grey squirrel eradication project in Italy. Gt. reshuffling Hum. Dimens. invasive alien species. IUCN, Gland 113-119.

Gibbs, E.P.J., 2014. The evolution of One Health: a decade of progress and challenges for the future. Vet. Rec. 174, 85-91.

Gibbs, L., Warren, A., 2015. Transforming shark hazard policy: Learning from ocean-users and shark encounter in Western Australia. Mar. Policy 58, 116-124. https://doi.org/10.1016/j.marpol.2015.04.014

Goetghebeur, M., Wagner, M., 2017. Identifying Value(s): A Reflection on the Ethical Aspects of MCDA in Healthcare Decisionmaking BT - Multi-Criteria Decision Analysis to Support Healthcare Decisions, in: Marsh, K., Goetghebeur, M., Thokala, P., Baltussen, R. (Eds.), . Springer International Publishing, Cham, pp. 29-46. https://doi.org/10.1007/978-3-31947540-0 3

Griffin, A.S., Callen, A., Klop-Toker, K., Scanlon, R.J., Hayward, M.W., 2020. Compassionate conservation clashes with conservation biology: should empathy, compassion, and deontological moral principles drive conservation practice? Front. Psychol. 11, 1139.

Hampton, J.O., Hyndman, T.H., 2018. Underaddressed animal-welfare issues in conservation. Conserv. Biol.

Hampton, J.O., Warburton, B., Sandøe, P., 2018. Compassionate versus consequentialist conservation. Conserv. Biol.

Hayward, M.W., Callen, A., Allen, B.L., Ballard, G., Broekhuis, F., Bugir, C., Clarke, R.H., Clulow, J., Clulow, S., Daltry, J.C., Davies-Mostert, H.T., Fleming, P.J.S., Griffin, A.S., Howell, L.G., Kerley, G.I.H., Klop-Toker, K., Legge, S., Major, T., Meyer, N., Montgomery, R.A., Moseby, K., Parker, D.M., Périquet, S., Read, J., Scanlon, R., Seeto, R., Shuttleworth, C., Somers, M.J., Tamessar, C.T., Tuft, K., Upton, R., Valenzuela-Molina, M., Wayne, A., Witt, R.R., Wüster, W., 2019. Deconstructing compassionate conservation. Conserv. Biol. 33, 760-768. https://doi.org/10.1111/cobi.13366

Huang, I.B., Keisler, J., Linkov, I., 2011. Multi-criteria decision analysis in environmental sciences: ten years of applications and trends. Sci. Total Environ. 409, 3578-3594. https://doi.org/10.1016/j.scitotenv.2011.06.022

Hursthouse, R., Pettigrove, G., 2018. Virtue Ethics. Stanford Encycl. Philos.

ICMO2, 2010. Natural processes, animal welfare, moral aspects and management of the Oostvaardersplassen, Report of the second International Commission on Management of the 
Oostvaardersplassen (ICMO2). The Hague/Wageningen, Netherlands. Wing rapport 039. November 2010.

IUCN-CEM, 2016. The IUCN Red List of Ecosystems. Version 2016-1. < http://iucnrle.org>. IUCN, 2019. The IUCN Red List of Threatened Species. Version 2019-1. $<\mathrm{http}: / /$ www.iucnredlist.org $>$.

Jarić, I., Courchamp, F., Correia, R.A., Crowley, S.L., Essl, F., Fischer, A., González-Moreno, P., Kalinkat, G., Lambin, X., Lenzner, B., 2020. The role of species charisma in biological invasions. Front. Ecol. Environ. https://doi.org/10.1002/fee.2195

Kareiva, P., 2014. New conservation: setting the record straight and finding common ground. Conserv. Biol. 28, 634-636. https://doi.org/10.1111/cobi.12295

Kareiva, P., Marvier, M., 2012. What is conservation science? Bioscience 62, 962-969. https://doi.org/10.1525/bio.2012.62.11.5

Katz, E., Light, A., 2013. Environmental Pragmatism, Environmental Philosophies. Taylor \& Francis.

Kunsch, P.L., Kavathatzopoulos, I., Rauschmayer, F., 2009. Modelling complex ethical decision problems with operations research. Omega 37, 1100-1108. https://doi.org/10.1016/j.omega.2008.11.006

Kuussaari, M., Bommarco, R., Heikkinen, R.K., Helm, A., Krauss, J., Lindborg, R., Öckinger, E., Pärtel, M., Pino, J., Rodà, F., 2009. Extinction debt: a challenge for biodiversity conservation. Trends Ecol. Evol. 24, 564-571. https://doi.org/10.1016/j.tree.2009.04.011

Lindsey, P.A., Frank, L.G., Alexander, R., Mathieson, A., Romanach, S.S., 2007a. Trophy hunting and conservation in Africa: problems and one potential solution. Conserv. Biol. 21, 880-883. https://doi.org/10.1111/j.1523-1739.2006.00594.x

Lindsey, P.A., Roulet, P.A., Romanach, S.S., 2007b. Economic and conservation significance of the trophy hunting industry in sub-Saharan Africa. Biol. Conserv. 134, 455-469. https://doi.org/10.1016/j.biocon.2006.09.005

Littmann, G., 2016. "The Needs of the Many Outweigh the Needs of the Few": Utilitarianism and Star Trek. Ultim. Star Trek Philos., Wiley Online Books. https://doi.org/https://doi.org/10.1002/9781119146032.ch12

Mace, G.M., 2014. Whose conservation? Science (80-. ). 345, 1558-1560. https://doi.org/10.1126/science.1254704

Mace, G.M., Lande, R., 1991. Assessing Extinction Threats: Toward a Reevaluation of IUCN Threatened Species Categories. Conserv. Biol. 5, 148-157. https://doi.org/https://doi.org/10.1111/j.1523-1739.1991.tb00119.x

MacLean, E.L., Matthews, L.J., Hare, B.A., Nunn, C.L., Anderson, R.C., Aureli, F., Brannon, E.M., Call, J., Drea, C.M., Emery, N.J., 2012. How does cognition evolve? Phylogenetic comparative psychology. Anim. Cogn. 15, 223-238. https://doi.org/10.1007/s10071-0110448-8

Miller, T.R., Minteer, B.A., Malan, L.-C., 2011. The new conservation debate: the view from practical ethics. Biol. Conserv. 144, 948-957. https://doi.org/10.1016/j.biocon.2010.04.001

Mills, L.S., Soulé, M.E., Doak, D.F., 1993. The keystone-species concept in ecology and conservation. Bioscience 43, 219-224. https://doi.org/10.2307/1312122

Norton, B.G., 2000. Biodiversity and environmental values: in search of a universal earth ethic. Biodivers. Conserv. 9, 1029-1044. https://doi.org/10.1023/A:1008966400817

Norton, B.G., 1986. Conservation and preservation: A conceptual rehabilitation. Environ. Ethics $8,195-220$. 
Norton, B.G., 1984. Environmental ethics and weak anthropocentrism. Environ. Ethics 6, 131148.

Ohl, F., Van der Staay, F.J., 2012. Animal welfare: At the interface between science and society. Vet. J. 192, 13-19. https://doi.org/10.1016/j.tvj1.2011.05.019

Oommen, M.A., Cooney, R., Ramesh, M., Archer, M., Brockington, D., Buscher, B., Fletcher, R., Natusch, D.J.D., Vanak, A.T., Webb, G., 2019. The fatal flaws of compassionate conservation. Conserv. Biol. 33, 784-787. https://doi.org/10.1111/cobi.13329

Oxford English Dictionary, n.d. anthropomorphism, n [WWW Document]. URL https://www.oed.com/view/Entry/8449?redirectedFrom=empathy (accessed 11.4.19a).

Oxford English Dictionary, n.d. consequentialism, n. [WWW Document]. URL http://www.oed.com.ezproxy.lib.monash.edu.au/view/Entry/39548? redirectedFrom=conseq uentialist\#eid8585927

Oxford English Dictionary, n.d. empathy, n. [WWW Document]. URL https://www.oed.com/view/Entry/61284?redirectedFrom=empathy (accessed 11.4.19c).

Oxford English Dictionary, n.d. neoteny, n [WWW Document]. URL https://www-oedcom.uaccess.univie.ac.at/view/Entry/126078?redirectedFrom=neoteny\#eid

Palazy, L., Bonenfant, C., Gaillard, J.-M., Courchamp, F., 2013. On the use of the IUCN status for the management of trophy hunting. Wildl. Res. 39, 711-720. https://doi.org/10.1071/WR12121

Palazy, L., Bonenfant, C., Gaillard, J.-M., Courchamp, F., 2011. Cat dilemma: too protected to escape trophy hunting? PLoS One 6, e22424. https://doi.org/10.1371/journal.pone.0022424

Palazy, L., Bonenfant, C., Gaillard, J.M., Courchamp, F., 2012. Rarity, trophy hunting and ungulates. Anim. Conserv. 15, 4-11. https://doi.org/10.1111/j.1469-1795.2011.00476.x

Palmer, C., McShane, K., Sandler, R., 2014. Environmental ethics. Annu. Rev. Environ. Resour. 39, 419-442. https://doi.org/10.1146/annurev-environ-121112-094434

Parker, I.M., Simberloff, D., Lonsdale, W.M., Goodell, K., Wonham, M., Kareiva, P.M., Williamson, M.H., Von Holle, B., Moyle, P.B., Byers, J.E., Goldwasser, L., 1999. Impact: toward a framework for understanding the ecological effects of invaders. Biol. Invasions 1, 3-19. https://doi.org/10.1023/A:1010034312781

Peterson, M.N., Peterson, M.J., Peterson, T.R., 2005. Conservation and the myth of consensus. Conserv. Biol. 19, 762-767. https://doi.org/10.1111/j.1523-1739.2005.00518.x

Proença, V.M., Pereira, H.M., Vicente, L., 2008. Organismal complexity is an indicator of species existence value. Front. Ecol. Environ. 6, 298-299. https://doi.org/10.1890/15409295(2008)6[298:OCIAIO]2.0.CO;2

Proulx, G., Brook, R.K., Cattet, M., Darimont, C., Paquet, P.C., 2016. Poisoning wolves with strychnine is unacceptable in experimental studies and conservation programmes. Environ. Conserv. 43, 1-2. https://doi.org/10.1017/S0376892915000211

Ramp, D., Bekoff, M., 2015. Compassion as a practical and evolved ethic for conservation. Bioscience 65, 323-327. https://doi.org/10.1093/biosci/biu223

Redpath, S.M., Young, J., Evely, A., Adams, W.M., Sutherland, W.J., Whitehouse, A., Amar, A., Lambert, R.A., Linnell, J.D.C., Watt, A., 2013. Understanding and managing conservation conflicts. Trends Ecol. Evol. 28, 100-109. https://doi.org/10.1016/j.tree.2012.08.021

Regan, T., 2004. The case for animal rights. Univ of California Press.

Rikoon, J.S., 2006. Wild horses and the political ecology of nature restoration in the Missouri Ozarks. Geoforum 37, 200-211. https://doi.org/10.1016/j.geoforum.2005.01.010

Rohwer, Y., Marris, E., 2021. Ecosystem integrity is neither real nor valuable. Conserv. Sci. 
Pract. n/a, e411. https://doi.org/https://doi.org/10.1111/csp2.411

Rolston III, H., 2003. Environmental ethics, in: Bunnin, N., Tsui-James, E.P. (Eds.), The Blackwell Companion to Philosophy, 2nd Edition. Blackwell Publishing, Oxford.

Russell, J.C., Jones, H.P., Armstrong, D.P., Courchamp, F., Kappes, P.J., Seddon, P.J., Oppel, S., Rauzon, M.J., Cowan, P.E., Rocamora, G., 2016. Importance of lethal control of invasive predators for island conservation. Conserv. Biol. 30, 670-672. https://doi.org/10.1111/cobi.12666

Salt, H.S., 1894. Animals' Rights: Considered in Relation to Social Progress. New York, London, Macmillan \& Co.

Sandler, R., 2012. Intrinsic Value, Ecology, and Conservation. Nat. Educ. Knowl. 3, 4.

Schuchert, P., Shuttleworth, C.M., McInnes, C.J., Everest, D.J., Rushton, S.P., 2014. Landscape scale impacts of culling upon a European grey squirrel population: can trapping reduce population size and decrease the threat of squirrelpox virus infection for the native red squirrel? Biol. Invasions 16, 2381-2391. https://doi.org/10.1007/s10530-014-0671-8

Shao, Y., Li, M., Zhang, W., Ji, Y., Hayes, D.J., 2018. World's Largest Pork Producer in Crisis: China's African Swine Fever Outbreak. Agric. Policy Rev. 2018, 1.

Shriver, A., 2006. Minding mammals. Philos. Psychol. 19, 433-442. https://doi.org/10.1080/09515080600726385

Singer, P., 2009. Speciesism and moral status. Metaphilosophy 40, 567-581. https://doi.org/10.1111/j.1467-9973.2009.01608.x

Singer, P., 1980. Utilitarianism and vegetarianism. Philos. Public Aff. 325-337.

Siurua, H., 2006. Nature above people: Rolston and "fortress" conservation in the south. Ethics Environ. 71-96.

Soulé, M.E., 2014. The "New Conservation." Conserv. Biol. 27, 895-897. https://doi.org/10.1111/cobi.12147

Soulé, M.E., 1985. What is conservation biology? Bioscience 35, 727-734. https://doi.org/10.2307/1310054

Stokes, D.L., 2007. Things we like: human preferences among similar organisms and implications for conservation. Hum. Ecol. 35, 361-369. https://doi.org/10.1007/s10745006-9056-7

Talbert, M., 2019. Moral Responsibility. Stanford Encycl. Philos.

Tam, K.-P., Lee, S.-L., Chao, M.M., 2013. Saving Mr. Nature: Anthropomorphism enhances connectedness to and protectiveness toward nature. J. Exp. Soc. Psychol. 49, 514-521. https://doi.org/10.1016/j.jesp.2013.02.001

Taylor, P.W., 2011. Respect for nature: A theory of environmental ethics. Princeton University Press.

Taylor, P.W., 1987. Inherent value and moral rights. Monist 70, 15-30.

Twigg, L.E., Parker, R.W., 2010. Is sodium fluoroacetate (1080) a humane poison? The influence of mode of action, physiological effects, and target specificity. Anim. Welf. 19, 249-263.

UNEP CBD, 2010. Strategic plan for biodiversity 2011-2020 and the Aichi targets, in: Report of the Tenth Meeting of the Conference of the Parties to the Convention on Biological Diversity.

Varner, G., 2011. Environmental ethics, hunting, and the place of animals, in: The Oxford Handbook of Animal Ethics. https://doi.org/10.1093/oxfordhb/9780195371963.013.0032

Varner, G., 2008. Utilitarianism and the evolution of ecological ethics. Sci. Eng. Ethics 14, 551573. https://doi.org/10.1007/s11948-008-9102-5 
bioRxiv preprint doi: https://doi.org/10.1101/2020.09.04.282947; this version posted April 14, 2021. The copyright holder for this preprint (which was not certified by peer review) is the author/funder, who has granted bioRxiv a license to display the preprint in perpetuity. It is made available under aCC-BY 4.0 International license.

Wallach, A.D., Batavia, C., Bekoff, M., Alexander, S., Baker, L., Ben-Ami, D., Boronyak, L., Cardilin, A.P.A., Carmel, Y., Celermajer, D., Coghlan, S., Dahdal, Y., Gomez, J.J., Kaplan, G., Keynan, O., Khalilieh, A., Kopnina, H., Lynn, W.S., Narayanan, S.R., Santiago-Ávila, F.J., Yanco, E., Zemanova, M.A., Ramp, D., 2020. Recognizing animal personhood in compassionate conservation. Conserv. Biol. https://doi.org/10.1111/cobi.13494

Wallach, A.D., Bekoff, M., Batavia, C., Nelson, M.P., Ramp, D., 2018. Summoning compassion to address the challenges of conservation. Conserv. Biol. 32, 1255-1265. https://doi.org/10.1111/cobi.13126

Warren, M.A., 2000. Moral Status: Obligations to Persons and Other Living Things, Issues in Biomedical Ethics. Oxford University Press, Oxford. https://doi.org/10.1093/acprof:oso/9780198250401.001.0001

Waytz, A., Iyer, R., Young, L., Haidt, J., Graham, J., 2019. Ideological differences in the expanse of the moral circle. Nat. Commun. 10, 1-12. https://doi.org/10.1038/s41467-019-12227-0

Weitz, N., Carlsen, H., Nilsson, M., Skånberg, K., 2018. Towards systemic and contextual priority setting for implementing the 2030 Agenda. Sustain. Sci. 13, 531-548. https://doi.org/10.1007/s11625-017-0470-0

Wilson, G.R., Edwards, M., 2019. Professional kangaroo population control leads to better animal welfare, conservation outcomes and avoids waste. Aust. Zool. 40, 181-202.

Wittmer, H., Rauschmayer, F., Klauer, B., 2006. How to select instruments for the resolution of environmental conflicts? Land use policy 23, 1-9. 


\section{Tables}

1139 Table1. Glossary of terms as they are used for the purposes of this paper.

\begin{tabular}{ll}
\hline Term & Definition \\
\hline Anthropocentrism & Value system that considers humans to be the sole, or primary, holder of \\
(strong) & moral standing, and therefore the concern of direct moral obligations. \\
& Non-human species are considered only to the extent that they affect the \\
& statisfation of felt preference of human individuals (Norton, 1984; \\
& Palmer et al., 2014; Rolston III, 2003). \\
\hline Anthropocentrism & Value theory in which all values are "explained by reference to \\
(weak) & satisfaction of some felt preference of a human individual or by \\
& reference to its bearing upon the ideals which exist as elements in a \\
& world view essential to determinations of considered preferences" \\
& (Norton, 1984). That is, the value of an individual or species is not only \\
& exploitative, but incorporates human experience and the non-utilitarian \\
& relationship between humans and nature. \\
"The attribution of human personality or characteristics to something & non-human, like an animal, object, etc." (Oxford English Dictionary). \\
Value system considering all living beings as the concern of direct moral & obligations (Palmer et al., 2014; Rolston III, 2003). \\
Anthropomorphism & Value system in which a group or collective has a higher value than the \\
individuals that compose it (Wallach et al., 2018). \\
Conservation approach inspired by virtue ethics based on four tenets: i) \\
do no harm; ii) individuals matter; iii) inclusivity (the value of an \\
individual is independent from the context of the population, e.g. \\
nativity, rarity, etc.); and iv) peaceful coexistence (Ramp and Bekoff, \\
2015; Wallach et al., 2018). \\
The group of beings considered to have moral responsibility in their \\
\end{tabular}


Community of

moral patients

Conservation

welfare

Consequentialism

Convergence

hypothesis

Deontology

Ecocentrism

Empathy

Impact (for the

purposes of the

framework, Eq.1)

Inherent value (our definition)
The group of beings considered to have intrinsic moral value, and towards which moral agents have moral obligations (Warren, 2000). The size of the group (referred to as the moral community in this work, for simplification) depends on the value system. For example, the moral community is restricted to humans in case of Anthropocentrism.

Conservation approach aiming at minimizing animal suffering (Beausoleil et al., 2018).

"An ethical doctrine which holds that the morality of an action is to be judged solely by its consequences" (Oxford English Dictionary).

"If the interests of the human species interpenetrate those of the living Earth, then it follows that anthropocentric and nonanthropocentric policies will converge in the indefinite future" (Norton, 1986).

A normative ethical theory considering that "choices are morally required, forbidden, or permitted" (Alexander and Moore, 2016).

Value system considering that species, their assemblages and their functions, as well as more broadly ecosystems, rather than individuals, are the concern of direct moral obligations (Palmer et al., 2014; Rolston III, 2003).

“The quality or power of projecting one's personality into or mentally identifying oneself with an object of contemplation, and so fully understanding or appreciating it." (Oxford English Dictionary). Empathy will influence the inherent value given to individuals from other species. Impact refers to any effect that modifies the wellbeing, health or resilience (for non-sentient beings) of an individual, from physical pain to emotional suffering and death (these notions being interrelated, but not equivalent).

Value possessed by an individual or collective, accounting for the effects of multiple context-dependent factors (e.g. charisma, anthropomorphism, organismic complexity, neoteny, cultural importance, religion, or parochialism). 
Intrinsic value

Invasive alien species

Moral community

Nativism

Nature despite people

Nature for itself

Nature for people

Neoteny

New conservation
Value possessed by an individual or collective as defined by a system of moral valuation, such as anthropocentrism, sentientism, biocentrism or ecocentrism. Intrinsic value is context-independent, and based on objective criteria (but the choice of criteria is subjective).

"Plants, animals, pathogens and other organisms that are non-native to an ecosystem, and which may cause economic or environmental harm or adversely affect human health" (Regulation (EU) No 1143/2014 of the European Parliament and of the Council of 22 October 2014 on the prevention and management of the introduction and spread of invasive alien species).

See "Community of moral patients".

Value system considering that species that have evolved in a given location have a higher value in this location than species that have evolved somewhere else. In nativism, value varies spatially (Wallach et al., 2018).

Management conceptual approach aiming at conserving biological diversity (focusing on species and habitats) specifically in response to human impacts on the environment, e.g. sustainable use (Mace, 2014). Management conceptual approach aiming at conserving biological diversity (focusing on wilderness and natural habitats) through human exclusion, for example through the creation of parks and protected areas (Mace, 2014).

Management conceptual approach aiming at conserving the components of nature beneficial to humans (focusing on ecosystems and their services) (Mace, 2014).

"The retention of juvenile characteristics in a (sexually) mature organism" (Oxford English Dictionary).

Discipline aiming at preserving biological diversity through the conservation of natural elements providing services and contribution to human wellbeing (Kareiva, 2014; Kareiva and Marvier, 2012). 
Normative postulate Value statements that make up the basis of an ethic of appropriate attitudes toward other forms of life (Soulé, 1985).

Parochialism Ideology in which moral regard is directed "towards socially closer and structurally tighter targets, relative to socially more distant and structurally looser targets", and, by extension, to species phylogenetically, cognitively, or in appearance closer to humans (Waytz et al., 2019).

People and nature Management conceptual approach considering that humans and nature are interdependent and therefore aiming at achieving compromises in the conservation of nature and human wellbeing (Mace, 2014).

Sentience The ability to experience phenomenal consciousness, i.e. the qualitative, subjective, experiential, or phenomenological aspects of conscious experience, rather than just the experience of pain and pleasure (Allen and Trestman, 2017).

Sentientism Value system considering sentient beings as the concern of direct moral obligations (Palmer et al., 2014; Rolston III, 2003).

Speciesism Value system in which some species are considered to have a higher value than others, for various possible reasons (Singer, 2009). Speciesism is often used to refer to the superiority of humans, which is a specific expression of speciesism as considered in this paper.

Suffering Negative emotion, sometimes called emotional distress, experienced by sentient beings, and which can result from different causes, including but not limited to physical pain (Dawkins, 2008; Farah, 2008).

Traditional conservation Discipline aiming at preserving biological diversity through the management of nature, and based on four value-driven normative postulates: "diversity of organisms is good," "ecological complexity is good," "evolution is good," and "biotic diversity has intrinsic value" (Soulé, 1985). Traditional conservation is rooted in ecocentrism.

Utilitarian value Virtue ethics Value given to an individual or collective by humans, based on its utility. Ethical doctrine that emphasizes the virtues, or moral character as the reason for action (Hursthouse and Pettigrove, 2018). 
1140 Table 2. List of factors to consider regarding the effects of environmental management actions 1141 from an environmental ethics perspective.

\begin{tabular}{ll}
\hline Factor & Influence on variables and outputs in Equations 1 to 5 \\
\hline Biotic interactions & The impact or suffering of individuals from one species can be \\
& caused by individuals from another species, either through direct \\
& or indirect interactions. Management actions can therefore also \\
& have non-trivial indirect impacts on some species.
\end{tabular}

Capacity to provide The presence of a specific species may increase the fitness/welfare ecosystem services of other species through the ecosystem services it provides. Since these effects can be difficult to quantify explicitly, the value of such species may be increased in Equations 1 to 4 to account for them.

\begin{tabular}{ll}
\hline Discounting rate & Rate at which impacts that occur in the future lose importance. \\
\hline Impact quantification & How the impacts of management actions are quantified is also \\
dependent on value systems, as some impacts (such as death) may \\
be considered incommensurable to others (such as suffering).
\end{tabular}


be beneficial on the long term once the ecosystem has stabilised.

Similarly, not culling some population may cause less suffering on

the short term, but increase it in the future by disrupting ecosystem

services, leading to population collapse due to lack of resources,

etc.

\begin{tabular}{ll}
\hline Uncertainty of impact & $\begin{array}{l}\text { The complexity of an ecological system can make the impact of } \\
\text { management actions on different species difficult to assess } \\
\text { precisely, therefore creating potential errors, especially in the } \\
\text { presence of multiple biotic interactions. This may lead to an } \\
\text { incorrect estimation of the consequences } C .\end{array}$ \\
\hline Uncertainty of value & Quantifying the value given by a person or a group of people to an \\
expressions and & individual is difficult, context-dependent, and highly subjective. \\
preferences & Sensitivity analyses on the distribution of values can be used to \\
& account for such uncertainty.
\end{tabular}




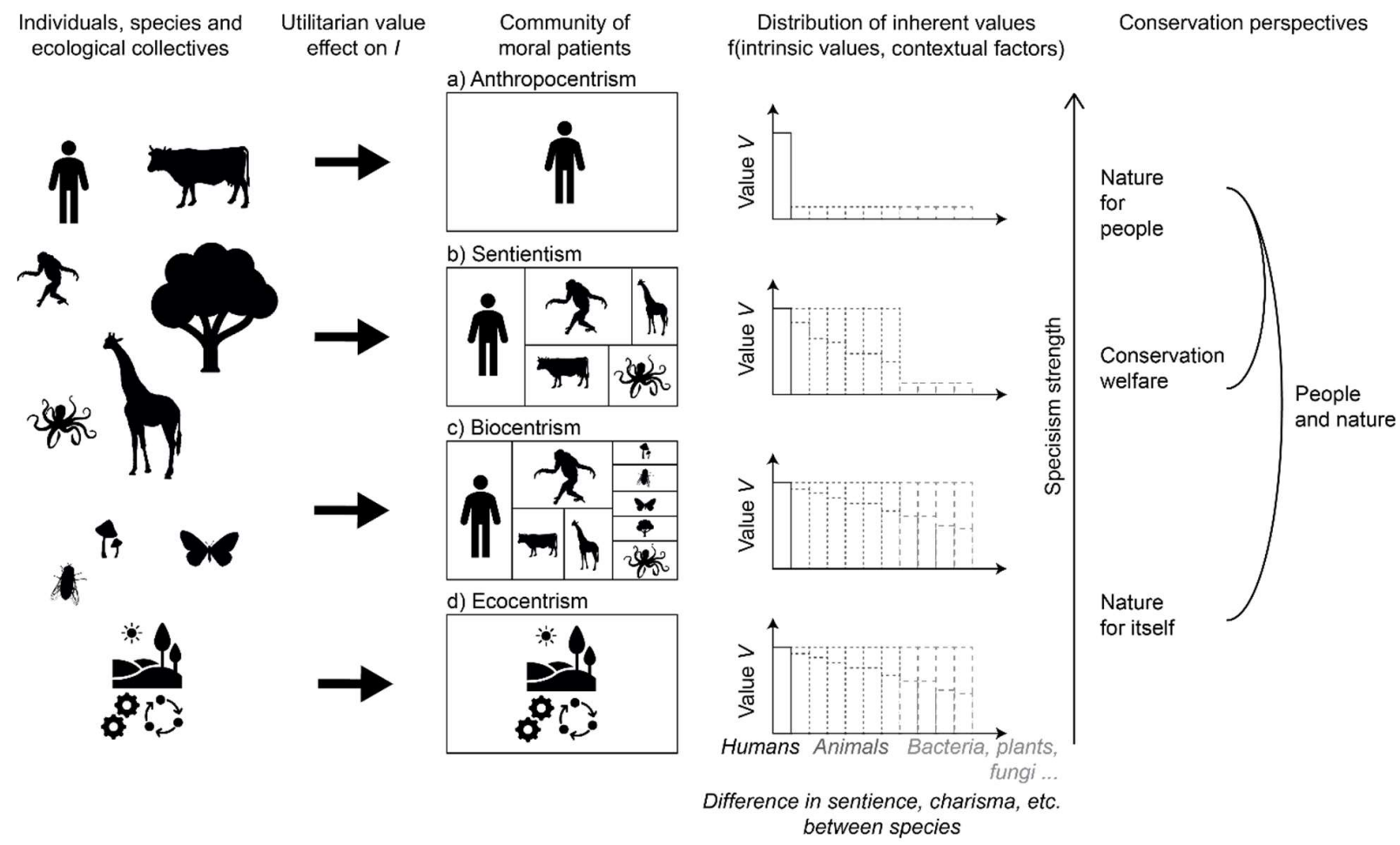

Figure 1. Differences between value systems influenced by a) anthropocentrism, b) sentientism, individuals intrinsically, but consider different moral communities, i.e. their values depend on the category of species they belong to, with \{humans $\} \in\{$ sentient beings $\} \in\{$ all living organisms $\}$. The intrinsic value, in combination with contextual factors, defines the inherent value of an individual. Ecocentrism, in contrast, is not based on individuals, but on ecological collectives,

1154 i.e. on species or on species assemblages and ecosystems. Species outside of the moral 1155 community may have a utilitarian value for species in the moral community (represented by the 1156 arrows), which will be reflected by changes in the impact variable. Note that species can have 1157 both an inherent and a utilitarian value. Within the moral community, species may have equal 1158 inherent values, but subjective perceptions and different value systems can assign different 1159 values to different species. The skewness of the value distribution then indicates the degree or 1160 strength of speciesism with respect to the species of reference, assumed here to be the human 1161 species, and is influenced by many factors, including charisma, cultural context, etc. Different 1162 value systems (or combination of) correspond to different conservation perspectives. 